\title{
Putting continuous quality improvement into accreditation: improving approaches to quality
} assessment

\author{
Ellie Scrivens
}

\begin{abstract}
The accreditation systems of the United States, Canada, and Australia have been restructured to reflect the adoption by health services of the industrial model of continuous quality improvement. The industrial model of quality makes assumptions about management structures and the relation of process to outcome which are not readily transferable to the assessment of quality in health care. The accreditation systems have therefore had to adapt the principles of continuous quality improvement to reflect the complex nature of health service organisations and the often untested assumptions about the relation between process and outcome.

(Quality in Health Care 1997;6:212-218)
\end{abstract}

Keywords: accreditation; continuous quality improvement; organisational performance

\section{Introduction}

Accreditation systems are traditionally a form of external peer review of organisational processes and structures (box 1). ${ }^{1}$ The heart of an accreditation system is standards, which describe good practice for a health service organisation such as a hospital. The focus for accreditation standards in the past has been on organisational policies and procedures rather than the organisation of clinical activity, although as will be shown later in this paper, this is now changing. Participation in accredi-

- A focus on organisational processes and procedures

- Written standards

- Compliance with the standards is assessed by trained surveyors with experience of working in the health service

- The degree of compliance is denoted by a graded score

- Recommendations are made by the surveyors for improving compliance

- Participation in the scheme is voluntary

- The findings of the surveyors are kept confidential to the participating organisation

- The whole process is administered by an independent board

Box 1 Traditional characteristics of accreditation systems. tation systems has been voluntary, a function of the fact that the organisations which administer accreditation systems have been self funding and autonomous bodies and therefore have had to sell their services to the health services with which they work. As a consequence, the degree of compliance with the standards, as assessed by external surveyors, usually teams of doctors, nurses, and administrators, was kept confidential to the participating organisation. The surveyors are charged with the task of helping the organisation to improve its processes and consequently they are asked to make recommendations to help in the achievement of compliance with the standards. Their findings and recommendations are sanctioned by an independent board whose members are usually representatives of professional bodies involved in the provision of health care. The board membership legitimates the standards and the survey process - without this there would be no credence for the accreditation activity.

This traditional or stereotypical model of accreditation prevailed for many decades. However, in the 1980s accreditation systems began to move away from this model. Newly created accreditation systems have arisen to meet the challenges posed by new service organisations-such as those providing community care. The older accreditation systems, those which have been termed the anglophone model of accreditation, ${ }^{2}$ found in Canada (in the form of the Canadian Council on Health Services Accreditation CCHSA), the United States (in many different accreditation systems but dominated by the Joint Commission on Accreditation of Healthcare Organisations: JCAHO), and Australia (as the Australian Council on Healthcare Standards ACHS), have evolved to reflect new approaches to delivery of health care. One of the most important forces in driving the recent developments in the design of accreditation systems has been the adoption of industrial models of quality management, most notably that of continuous quality improvement by health services. This paper describes the early models of accreditation, and how these have been modified during the 1990 s by accreditation systems to incorporate the principles of continuous quality improvement.

\section{Early models of accreditation (box 2)}

The early models of accreditation concentrated on organisational processes as the main means to assure the quality of the environment in 
(1) The organisation of physicians and surgeons with privileges to practice in the hospital

(2) The restriction of staff membership to physicians and surgeons who were fully qualified, competent, and worthy in character and in matters of professional ethics

(3) The establishment of rules, regulations, and policies governing the professional work of the hospital, and at regular intervals staff review and analyse their clinical experience in the various departments of the hospital-such as medicine, surgery, obstetrics, and the other specialties; the clinical records of patients, both free and paying, to be the basis for such review and analyses

(4) That accurate and complete records be written for all patients and filed in an accessible manner in the hospital

(5) That diagnostic and therapeutic facilities under competent supervision be made available for the study, diagnosis, and treatment of patients

Box 2 The first accreditation standards concerned.

which clinical practice occurred. ${ }^{1}$ The dominant assumption underpinning this approach was that clinicians would only practice effectively, and health resources be used efficiently, if the organisational structures and processes operated according to agreed standards. This view was held from 1917, when the American College of Surgeons established what was termed the Hospital Standardisation Programme with the intention of stimulating institutions with inferior equipment and standards to raise the quality of their work. ${ }^{3}$ In the early 1970s accreditation systems moved with a series of systematic review procedures towards non-structural measures, which used criteria for asessing conformity of standards, and therefore, it was argued, measured the quality of care. ${ }^{4}$ This reflected the changing views in industry which were transferred to health care. Quality was being seen as something produced by organisations, and it therefore needed to be monitored and defined. ${ }^{5}$ Therefore the process of assessing compliance with standards changed from using surveyor judgement to decide whether a standard was met, to using tightly specified criteria against which surveyors could put scores. The scores could then be summed to provide a numerical score which indicated the extent of compliance with a standard.

During the 1980s, the healthcare industry was developing methods through which the results of care could be assessed, concentrating on the development of outcome measures. Accreditation systems recognised the need to accommodate this change in emphasis. In 1991, for example, the CCHSA announced a major change to the philosophy underlying its approach and the content of its standards acknowledging that health service organisa- tions thought that "current standards and accreditation process were incompatible with the philosophies and foci upon which they now operated... if CCHSA did not make major adjustments to the standards and process used for accreditation, both would quickly become irrelevant for them."13

In 1986, the JCAHO announced its change in approach under the banner the agenda for change. ${ }^{7}$ This initiative was intended to show that the JCAHO had moved from quality assurance to what they termed quality management-a search for quality improvement which involved a continuous search with data analysis for improved quality. Quality improvement would be promoted through a reduction in the number and complexity of standards, refocusing of the remaining standards on key processes, development of performance indicators related to the key processes, development of methods for data collection, the establishment a national comparative database, and improvements in the survey process to support those goals. This followed the then generally accepted views of continuous quality improvement.

However, during the 1980 s, industry was moving to a different, more complex approach, in which the causes of outcomes or the results of the manufacturing process could be understood and thereby modified. ${ }^{5}$ The healthcare sector, which was beginning to struggle with the complexities of measuring health and health service outcomes as it started to take on board the ideas from industry, found itself facing the need to redefine its approach to quality, looking to the causes of poor quality as opposed to simply assessing the outcome of service delivery. In 1991 the CCHSA introduced new standards which were aimed towards process and outcome, rather than the previous emphasis on structure. However, it was clear that "...further movement toward outcomes was necessary and needed fairly rapidly. In other words, these new standards were seen to be only a bridge to a more significant change." "Accreditation systems had to review their approach and modify it to create a coherent framework in which quality could be reviewed and also improved. For the JCAHO and the CCHSA this meant embracing fully the principles of continuous quality improvement and adapting them to form a framework for quality assessment which would have meaning for the health services they served.

\section{Principles of continuous quality improvement}

The industrial model had, over a period of decades, consolidated into what is now called continuous quality improvement (sometimes referred to as total quality management). ${ }^{8}$ Continuous quality improvement has no single definition or model on which it is based. ${ }^{9}$ Some management theorists and practitioners arrived at an agreement on the characteristics of continuous quality improvement with different approaches to implementation. Common to the approaches are the principles that continuous quality improvement has to 
- Involves everyone in the organisation

- Concerned with all the internal organisational processes

- Views quality as the result of every single step or process

- Everyone in the organisation should take responsibility for quality

- Emphasis on reducing wastage of resources

- Focuses on external needs predominantly those of customers

- Requires leaders to support improvements in the production systems

- Places sound statistical analysis at the centre of any search for quality improvement

Box 3 The principles of continuous quality improvement.

involve everyone in the organisation and is concerned with all the internal organisational processes. Quality is the result of every single step or process for which everyone in the organisation should take responsibility, particularly being concerned with the elimination of inefficiency; it is concerned with managing external needs; requires leaders to support systemic improvement; and places sound statistical analysis at the centre of any search for quality improvement. ${ }^{59}$

\section{Impact of continuous quality improvement on accreditation systems}

For healthcare systems, the arrival of continuous quality improvement coincided with the maturing of health service management about cost containment and efficiency in the use of resources, and about standardising the quality of medical care. Quality was seen as something which was more than just the product of the actions of a clinician on a patient. The role of the patient was recognised in determining quality. The interpersonal aspects of clinical care were recognised to impact on the technical aspects. ${ }^{10} 11$ Public concerns about the safety and efficacy of treatments made healthcare managers and policy makers begin to seek out new ways of approaching quality and adapting the methods used to describe and manage health services.

Accreditation systems were accommodating to this broadening view of the determinants of quality which went hand in hand with the principles of continuous quality improvement. Patient focused care, assessing quality as the patient's experience, caused standards to be rewritten accordingly. But for accreditation systems the adoption of continuous quality improvement as a prevailing management philosophy presented an additional challenge. In the early 1990s, in North America, the whole approach of external review, central to accreditation, was being criticised by some proponents of continuous quality improvement as inappropriate for the promotion of continuous improvement in quality matters. ${ }^{12}$ External review, it was claimed, was negative and punitive laying blame at the door of those professionals who made mistakes, rather than encouraging striving for improvement. Although this criticism was directed mainly at professional peer review intended to identify bad practice, accreditation systems were subject to the same accusation. The original emphasis of accreditation on organisational processes and procedures meant that clinical activity was excluded from its considerations. The quality of clinical activity was controlled with peer review which aimed to identify the bad practice of individual practitioners and was accepted by the accreditation systems. The proponents of continuous quality improvement therefore criticised the JCAHO for targeting bad care, ${ }^{4}$ whereas the ACHS was upbraided for having no relevance to the practice of medicine. ${ }^{14}$

Accreditation systems had previously claimed that because they offered recommendations for change, and they supported organisations in the process of self review, both before the survey and between surveys, they were focused on organisational self development. ${ }^{13}$ As the arguments mounted that quality could only be promoted through the internal review of processes, and would not prosper under external review, accreditation systems found it hard to counter the claims that they were at best of quality assessment rather than quality assurance and at worst instruments of regulation. They had, therefore, to develop an approach which would encompass the principles of continuous quality improvement within a framework compatible with external review.

\section{Assimilation of continuous quality}

\section{improvement into accreditation}

As noted earlier, accreditation systems have to reflect current health service thinking. In seeking an appropriate model to guide the necessary changes, there were several difficulties in finding a workable and acceptable model of quality, based on the industrial model of continuous quality improvement. In hospitals, in the past, three different hierarchies were understood: management, nursing, and doctors. ${ }^{15}$ This had allowed accreditation systems to concentrate on what was considered to be the province of the management hierarchy-organisational design and organisational processes-leaving the medical and nursing hierarchies to approach quality control and assurance of the clinical aspects of work. However, the industrial model of continuous quality improvement assumes one management structure, and assumes that senior management can influence the activities of the staff who work within the organisation. ${ }^{8}$ So the accreditation systems had to work around this limitation by changing assumptions about management structures in continuous quality improvement as applied to health care.

\section{Emphasis on team work}

The JCAHO, to accommodate the demands associated with continuous quality improvement, defined the concept as the removal of structural barriers and the creation of an environment in which team work could be 
emphasised. It recommended an organisational structure designed to maximise cooperation and ensure a single purpose. ${ }^{16}$ To accommodate these changes, the JCAHO had to radically change the whole structure and content of the standards it used. ${ }^{17}$ To make the concept workable in a standards based approach to quality, the JCAHO adapted the concept of continuous quality improvement to meet its own needs and to some extent redefined it by drawing a distinction between total quality management and continuous quality improvement. The Chief Executive claimed that total quality management suggested that there might be a single management structure, whereas continuous quality improvement permitted more flexibility in management structures ${ }^{18}$ which was considered to be vitally important in the management of healthcare organisations. The CCHSA Council, responding later to the changing demands of healthcare systems, chose to use the term continuous quality improvement and also devised its own definition of continuous quality improvement as " $\mathrm{A}$ management philosophy and system which involves the boards of directors, managers and health professionals and other employees in the continuous improvement of work processes and the outcomes of patient care. It involves the application of statistical methods and group process tools to reduce waste, duplication and unnecessary complexity in its work. Its goal is to meet or exceed the needs and expectations of patients, professionals, suppliers and the community."

To promote the concept of cooperation between different professional groups employed within healthcare organisations, the JCAHO and the CCHSA Council both identified leadership in planning as a major aspect of a continuous quality improvement approach. ${ }^{19}{ }^{20}$ Healthcare organisations have to plan the future direction of services, and planning was therefore seen as a significant process. But there are considerable implications of this assumption for the delivery of health care. The relationship of doctors, whose individual activities affect patient care, cannot be readily dictated by health services management. Healthcare organisations are not amenable to top down imposition of ideas, particularly in the area of quality of care. Planning of health care therefore has to be undertaken in line with current medical thinking, and also has to accommodate the activities and practices of individual clinicians. Where continuous quality improvement or total quality management models have been imposed on health service organisations, implementation has been judged to fail. ${ }^{10}$ The industrial models of continuous quality improvement promoted what Ovretveit has described as "full scale and complete organisational change driven by top management" which his research showed rarely involved doctors or was led by doctors. ${ }^{8}$ As a consequence, doctors continued to practice and ignored management injunctions to change. ${ }^{15}$ This phenomenon was familiar to the organisationally based accreditation systems who well recognised that their work was either rejected or ignored by clinicians practising in the hospitals they surveyed. ${ }^{21} 22$ To make accreditation more acceptable to clinicians, accreditation systems had to become more relevant to clinical activity and adopt a management model more appropriate to healthcare organisations. This new agenda gave rise to what was termed the patient centred or client centred approach.

\section{Patient centred accreditation}

The original model for the writing of accreditation standards was to assume that hospitals (and by derivation, all other health services) were made up of a series of organisational building blocks, usually departments. ${ }^{23}$ This was being increasingly criticised as "fragmentary and uncohesive" failing to provide "a patient-centred perspective within the individual health care facility, nor does it readily encourage a problem solving attitude to organisational decision making and practice."24 Therefore another evolution in the accreditation process, associated with the interpretation of continuous quality improvement, has been to view hospitals in a way which reflects their activities as processes of patient care-that is, as functions in the delivery process, rather than describing them as groups of independent organisational units or departments. The JCAHO 1996 manual claims that "the patient focused and organisational functions and their related process and activities described in this manual are similarly interrelated. In most hospitals they represent a seamless, integrated series of activities." ${ }^{20}$ The standards have therefore been reconfigured to represent three main types of functions: patient focused; organisational; and structures with functions. This division is designed specifically to be compatible with the continuous quality improvement based industrial model of quality improvement of the Malcolm Baldridge Quality Award. Patient focused functions, described as the primary mission of hospitals, cover patients' rights and organisational ethics; assessment of patients; care of patients; and education through promoting healthy behaviour. Organisational functions cover improving organisational performance through patient outcomes; leadership through planning and coordination; management of the environment of care; management of human resources; management of information and surveillance; and prevention and control of infection. The third section considers governance; management; medical staff; and nursing.

The Canadian approach is very similar to that of the JCAHO. They have identified the same structure with functions which they have termed support processes. In what they have termed a client centred approach, they reframed their standards of patient care to reflect the patient care process divided into admission, assessment, care planning, care delivery, evaluation of care, discharge planning, and follow up. ${ }^{6}$ Leadership was identified as a separate category. To reflect their commitment to outcomes, specific standards were created which required indicators of quality to be 
established by the organisation for all major processes. $^{19}$

\section{Systems philosophy}

Furthermore, the new approaches to quality improvement suggested that, rather than using inspection to correct unusual errors, the emphasis should move to improving the processes of care to ensure that desired outcomes were produced..$^{24}$ The theory being that substandard care is the result of poor process design, inadequate information, and poor training rather than individual incompetence or greed. ${ }^{5}$ This new emphasis, on the failings of the system rather than the individual in producing poor performance, lay at the heart of continuous quality improvement and was probably the most important contribution of it to the structuring of the philosophy of accreditation. Now accreditation systems could claim that they were helping to develop systems for improving care, rather than just checking on departmental procedures. The new approach required that accreditation systems be less prescriptive in the format of their standards, and more flexible in their approaches to local circumstances and conditions. ${ }^{16}$ This decision happily coincided with the need to reduce the number of standards which had, in the case of the JCAHO reached nearly 4000 to describe the work of a hospital.

The accreditation systems were also caught in the demands of continuous quality improvement for statistical analysis which would lead to improvement in services, shown as improvements in clinical activity as well as organisational performance. Accreditation systems, therefore, should not only promote the concept of quality improvement, but also maintain a role as the assurers of quality. This has resulted in a search for indicators which suggest overall organisational performance and clinical performance, and yet retain standards which would rectify failings in performance.

For accreditation systems, the move from assessing compliance with standards to outcome measures presented problems not because devising indicators is a difficult task in itself, but also because it involved a fundamental change in the basic philosophy underpinning accreditation. Standards suggest how an organisation or a system should operate to provide care. They ensure an initial assessment of what a healthcare organisation is capable of doing. Outcome indicators, on the other hand, offer an assessment of how well the care has been provided. They are final assessments of system functioning. Collopy describes the philosophy behind the changes in the Australian system of accreditation: "If it is accepted that the purpose of a hospital is to provide the optimum environment to treat compromised people - that is, patients - it is appropriate to address the environment firstly in the development of an accreditation process, and then move to the assessment of treatment, i.e. the outcomes of care."14

The search for indicators had started in the 1980s. In 1985, discussions began between the ACHS and the medical colleges to consider "... the concept of introducing some objective measures of care in hospital, measures which could be addressed during an accreditation survey." 26

This move had been initiated to meet the growing demands to make accreditation more relevant to the medical profession, who thought that accreditation did not necessarily show that performance was satisfactory. ${ }^{27}$ In 1989 the committee of presidents of the Australian Medical Colleges expressed their support for the development of measures known as clinical indicators. Funding was obtained from the Federal Health Department and private industry for the ACHS to establish its indicator programme, the care evaluation program. ${ }^{1+}$

The JCAHO tried to develop what it termed the indicator measurement system which would provide a comparative database to allow hospitals to compare their performance with others. ${ }^{28}{ }^{29}$ The indicator measurement system consists of several sentinel events and aggregate data indicators that are associated with quality of care. ${ }^{28}$ The relation between the indicators and quality improvement was not stated and not proved and the arguments behind national comparisons and the quality improvement process foundered. The JCAHO abandoned its hope to make this data collection compulsory, and has left it as a voluntary activity for hospitals that find it useful. ${ }^{528}$

The pressure to pursue indicators was reinforced by the adoption of continuous quality improvement which emphasised statistical analysis to show systems failure. In health care this meant relating processes to outcomes which proved to be one of the most difficult challenges facing accreditation systems. Not only did it require the production of outcome measures, it also meant that accreditation systems could no longer be assumed to be only to check on the environment in which care was provided. "A total quality initiative should ensure that the supporting functions are as effective as possible to facilitate its prime purpose of patient care." ${ }^{30}$ Accreditation standards now had to begin to consider clinical management as well as organisational management.

Also, quality in health care has to consider not only the care provided to individual patients but also has to meet a public accountability agenda of organisational performancerelating use of resources to outcomes achieved. Accreditation systems have therefore also begun to consider the issue of how to assess how well a healthcare organisation is performing.

\section{Organisational performance}

Accreditation systems have, therefore, become increasingly important in measuring and comparing what has been termed organisational performance defined by the JCAHO as "the way in which a healthcare organisation carries out or accomplishes its important functions". ${ }^{29}$ The early emphasis on structure had been based on the assumption that consensus about organisation would lead to more efficient and 
effective health care. ${ }^{31}{ }^{32}$ It is not agreed that there is unequivocal evidence that organisation led to improved outcomes. ${ }^{33}{ }^{34}$ Although there is limited evidence that the organisational design of care is important ${ }^{35}{ }^{36}$ accreditation systems have generally conformed to Donabedian's dictum "What we do know suggests that the relationship between structural characteristics and the process of care is rather weak. From these characteristics, we can only infer that conditions are either inimical or conducive to good care." 31 Even so, the assessment of organisational performance is still justified by an assumption that good processes will lead to good patient outcomes. "A fundamental thesis that drives performance improvement activities is that an organisation's level of performance in the aggregate or with respect to specific functions, determines in part the level of patient health outcomes it achieves." 37

The Canadian and Australian accreditation councils have decided on an incremental approach to the development of comparative indicators. Although still seeking ways of assessing overall organisational performance, the ACHS has selected a few hospitalwide indicators for comparative use, ${ }^{14}$ and the CCHSA also has a few, although they have chosen to allow hospitals to choose their own indicators. $^{38}$ When an appropriate bank of indicators is established they will be tested for validity and then tested within the service.

The JCAHO accepted the United States Institute of Medicine's view that "quality of care is a judgement shaped by the interests of the individual or group making the judgement," whereas performance by contrast is "something an organisation does as in processes or achieves as in outcomes." 39 Quality improvement therefore comes from allowing judgements to be made on the basis of performance data. In this way the accreditation systems have chosen to encourage the pursuit of quality through developing indicators that allow and standards that encourage the continued assessment of organisational performance. The accreditation systems have therefore realigned themselves to promoting the idea that continually questioning what has happened will lead to better processes and therefore better outcomes.

\section{Informing consumers}

Continuous quality improvement means that the needs of customers are met. As medicine has begun to accept the interpersonal, as well as the technical aspects of care, so accreditation systems have been able to move their standards to question whether current views about the appropriate way to deal with patients are adequately embraced by healthcare organisations. The view is that there should be a set of values by which patients are treated-providing them with information and ethics on how they should be treated, and considering their opinions are part of the client or patient centred approach.

Unlike most other accreditation systems the JCAHO has made it part of its approach to make the information about its visits public. ${ }^{40}$
This has been a radical change in the use of accreditation information. Although the JCAHO grew from an initiative in 1917, the hospital standardisation programme was supposed to provide the public with some means of recognising those institutions devoted to the highest ideals of medicine ${ }^{3}$ this has not been an aim of accreditation. ${ }^{1}$ Most accreditation systems hold firm to the view that if accreditation is about self development then the results of surveys should be held confidential to the client organisation. In breaking this tradition, the JCAHO has recognised the fact that potential patients or clients of healthcare services may wish to know more about the organisations they will deal with. But in so doing, the role of the accreditor has changed-from organisational consultant to one of public regulator. ${ }^{41}$ The impact of continuous quality improvement has been far reaching.

\section{Conclusion}

The requirement of continuous quality improvement is to ensure that the organisation is continually striving towards quality improvement. Accreditation systems have changed in approach enormously to implement this philosophy. However, they are bound by the assumptions which dictate current thinking in health care, about patient care, about the rights of patients, about the relation between processes and outcomes. As knowledge about these relations change, so assumptions about the variables determining quality change. Accreditation systems have to continue to reflect this. Also, the purpose of quality control is changing. Continuous quality improvement is interpreted to mean the search for better patient outcomes. But accreditation is a tool for monitoring organisational performance and for monitoring that the delivery of health care is conducted in an acceptable way. At present, accreditation systems are involved in a search to find a method for promoting an approach to heathcare management which encourages the search for improvement, and assessing against that model how well the organisations are performing. As the understanding of the impact of health care changes, so accreditation systems are forced to redefine the terms to describe healthcare organisations, and to change the criteria by which success is determined. Continuous quality improvement has radically changed the approach of accreditation systems-and doubtless the changes have not finished yet.

The changes driven by continuous quality improvement have caused accreditation systems to redefine the activities of the hospital in ways which reflect the process of patient care rather than the administrative structures. As the accreditation systems have sought more market share, they have developed standards for organisations other than hospitals, embracing the whole range of health services from mental health to ambulatory care. But they have been able to retain a focus on the organisations of health care. However, the traditional organisational forms of health care are increasingly threatened. New ideas of patient care cut 
across organisational boundaries and there is a growing need to find new ways of describing healthcare systems. The JCAHO has begun to define standards for healthcare networks which encompass a range of services purchased by third party funders. The next challenge facing accreditation systems will be to describe the more complex patterns of service delivery which will provide care and to monitor their attempts to promote quality. ${ }^{42}$ The next decade will demand that the models of quality underpinning accreditation be embedded in new descriptions of complex service interrelations-the philosophy of continuous quality improvement will need to be adapted yet again if it is to provide an appropriate framework for assessing quality through accreditation systems in the next century.

1 Scrivens E. Accreditation protecting the professional or the consumer. Buckingham: Open University Press. 1995.

2 Scrivens E, Klein R, Steiner A. Accreditation: the anglophone model. Health Policy 1995; 34: 193-204.

3 Roberts J S, Coale JG, Redman RR. A history of the Join Commission on Accreditation of Hospitals. $¥ A M A 1987$ 258:936-40.

4 Brennan TA, Berwick DM. New rules. San Francisco: Jossey Bass, 1996.

5 Decker MD. Continuous quality improvement. Infect Control Hosp Epidemiol 1992;13:165-9.

6 Heidemann E. Client-centred accreditation. International fournal of Health Planning and Management. 1995;10:209 22.

7 O'Leary D. Accreditation in the quality improvement mould - a vision for tomorrow. Quality Review Bulletin 1991;17 $72-5$

8 Ovretveit JA. Why total quality management programmes fail in European public health services - and what to do about it. Paper presented to the Quality in Services Conference. Stanford, Connecticut: 1994.

9 Morgan C, Murgatroyd S. Total quality management in the public sector. Buckingham: Open University Press, 1994.

10 Donabedian A.The Lichfield Lecture: quality assurance in health care: consumers' role. Quality in Health Care 1992;1. health care:

$11 \mathrm{Lohr} \mathrm{K}$. Outcome measurement: concepts and questions. Inquiry 1988;25:37-50.

12 Berwick D. Continuous improvement as an ideal in health care. $N$ Engl f Med 1989;320;53-6.

13 Joint Commission on accreditation of health care organisations. Principles of organizational and management effective ness for health care organizations. Illinois: Joint Commission on Accreditation of Health Care Organisations, 1989.

14 Collopy B. Extending facility accreditation to the evaluation of care: the Australian experience. International fournal of Health Planning and Management. 1995;10:223-30.

15 Kritchevsky SB, Simmons BP. Continuous quality improvement concepts and applications for physician care. $\mathscr{f} A M A$ 1991;13:1817-23.

16 Joint Commission on accreditation of healthcare organisations. Accreditation manual for hospitals 1994. Vol 1 Standards. Illinois: Joint Commission on Accreditation of Healthcare Organisations, 1994
17 Berman S, Benes R, Carol R. National demonstration project and Joint Commission forums celebrate successes and address future needs in quality improvement II. Quality Review Bulletin 1992;108-13.

18 O'Leary D. A concept in search of fulfillment. Fournal of MAG. 1987;569-72.

19 Canadian Council on Health Services Accreditation. Standards for acute care organisations: a client centred approach. Ottawa: Canadian Council on Health Services Accreditation, 1994.

20 Joint Commission on accreditation of healthcare organisations. 1996 Comprehensive accreditation manual for hospitals. Illinois: Joint Commission on Accreditation of Healthcare Organisations. 1996.

21 Longo DR, Wilt JE, Laubenthal RM. Hospital compliance with Joint Commission standards: findings from 1984 surveys. $Q R B$ 1986;12:388-94.

22 Amos BJ. Medical problems in hospitals: what has the Australian Council on Hospital Standards discovered? Australian Clinical Reviews 1985;5:44-6.

23 Scrivens E. Evaluating accreditation systems. European fournal of Public Health 1997;7:4-8.

24 Lloyd PJ. The Australian model of hospital accreditation: discussion. Australian Health Reviews 1997;10:171-8.

25 Jenks S, Wilensky GR. The health care quality improvement initiative. $\mathcal{F} A M A$. 1992;7:900-3.

26 Collopy BT. Clinical indicators as a stimulus to QA in hospitals. An early report. Int $\mathcal{f}$ Qual Health Care 1994;6:3318 .

27 Collopy B, Balding C, The Australian development of national quality indicators in health care. foint Commission fournal on Quality Improvement 1993;19:510-6.

28 Schyve P. Relating performance measurement and accreditation. International fournal of Health Planning and Management 1995;10:231-42.

29 Joint Commission on Accreditation of Healthcare Organisations. The measurement mandate. Oakbrook Terrace, Illinois: The Joint Commission, 1993.

30 Hereford and Worcestershire FHSA. Total quality in general practice. Hereford: Hereford and Worcestershire FHSA. practice.

31 Donabedian A. The quality of care: how can it be assessed? FAMA. 1988;260:1743-8.

32 Brooks T, Pitt C. The standard bearers. Health Service four nal 1990;100:1286-7.

33 Nash DB. Is the quality cart before the horse? $\mathcal{F} A M A 1992$ 268:917-8.

34 Palmer H, Reilly MC. Individual and institutional variables which may serve as indicators of quality of medical care Med Care 1979;18:693-717.

35 Knaus WA, Draper EA, Wagner DP, et al. An evaluation of outcome from intensive care in major medical centers. Ann Intern Med 1986;104:410-8

36 Sofaer S, Myrtle RC. Inter-organisational theory and research: implications for health care management, policy, and research . Med Care Rev 1991;48:371-409.

37 Donabedian A. Evaluating the quality of medical care. $\mathrm{Mil}$ bank Memorial Fund Quarterly 1966;3:166-203.

38 Canadian Council on Health Services Accreditation. $A$ guide to the development and use of performance indicators. Ottawa, Canada: Canadian Council on Health Services Accreditation, 1996.

$39 \mathrm{Lohr}$ KN, ed. Medicare: a strategy for quality assurance. Vol 1. Washington, DC: Institute of Medicine, 1990

40 Skolnick AA. Joint Commission will collect, publicize outcomes. $\Im A M A$ 1993;270:165-71.

41 Scrivens $\mathrm{E}$ A taxonomy of the dimensions of accreditation systems. Social Policy and Administration 1996;30:114-24.

42 Scrivens E. Accreditation and primary care services Report to NHS Executive West Midlands. Keele: Centre for Health Planning and Management, Keele University, 1997. 